\title{
Chronic intermittent hypoxia and obstructive sleep apnea: an experimental and clinical approach
}

This article was published in the following Dove Press journal:

Hypoxia

27 April 2016

Number of times this article has been viewed

\section{Emilia Sforza \\ Fréderic Roche}

Service de Physiologie Clinique et de l'Exercice, Pole NOL, CHU, EA SNAEPIS 4607, Faculté de Médecine J. Lisfranc, UJM Saint-Etienne, Université de Lyon, Saint-Etienne, France
Correspondance: Emilia Sforza Service de Physiologie Clinique, CHU Nord - Niveau 6, F-42055 Saint-Etienne Cedex 2, France

Tel +33477828300

Fax +33477828447

Email emilia.sforza@gmail.com

\begin{abstract}
Obstructive sleep apnea (OSA) is a prevalent sleep disorder considered as an independent risk factor for cardiovascular consequences, such as systemic arterial hypertension, ischemic heart disease, cardiac arrhythmias, metabolic disorders, and cognitive dysfunction. The pathogenesis of OSA-related consequence is assumed to be chronic intermittent hypoxia (IH) inducing alterations at the molecular level, oxidative stress, persistent systemic inflammation, oxygen sensor activation, and increase of sympathetic activity. Overall, these mechanisms have an effect on vessel permeability and are considered to be important factors for explaining vascular, metabolic, and cognitive OSA-related consequences. The present review attempts to examine together the research paradigms and clinical studies on the effect of acute and chronic IH and the potential link with OSA. We firstly describe the literature data on the mechanisms activated by acute and chronic IH at the experimental level, which are very helpful and beneficial to explaining OSA consequences. Then, we describe in detail the effect of IH in patients with OSA that we can consider "the human model" of chronic IH. In this way, we can better understand the specific pathophysiological mechanisms proposed to explain the consequences of IH in OSA.
\end{abstract}

Keywords: hypoxia, intermittent hypoxia, experimental studies, obstructive sleep apnea

\section{Introduction}

Prevalence studies conducted over the past decade have demonstrated that up to 5\% of adults in Western countries are likely to have undiagnosed obstructive sleep apnea (OSA). When we consider the severity of the disease stratified according to an apneahypopnea index $(\mathrm{AHI}) \geq 5$ and an $\mathrm{AHI} \geq 15$, the prevalence estimate is from $3 \%$ to $28 \%$ for mildly severe cases (AHI $>5$ ) and from $1 \%$ to $14 \%$ for moderately severe cases (AHI >15). When laboratory studies are considered, the results of cohorts in Wisconsin (1,490 subjects), ${ }^{1}$ Pennsylvania (932 subjects), ${ }^{2,3}$ Spain (455 subjects),${ }^{4}$ and the Sleep Heart Health Study $(6,642 \text { subjects })^{5}$ have demonstrated that one out of every five adults has at least an AHI $>5$ and one out of every 15 has at least an AHI $>15$. Age and sex are two factors implicated in the prevalence of the disease, with men having two- to threefold greater risk for OSA compared to women, and for people older than 60 years having an AHI $>15$ is approximately 1.7-fold higher than middle-aged persons. ${ }^{6,7}$ The reason for the sex risk difference was initially explained by the protective role of progesterone and estrogens, ${ }^{8}$ as well as exposure to other risk factors in men such as fat deposition, smoking, and alcohol intake. The most probable explanation is that there are clear sex and age differences in the upper airway shape, genioglossal muscle activity, and craniofacial morphology, accounting for a higher male risk. ${ }^{9}$ 
However, recent studies proposed that the increase of OSA in postmenopausal women may be explained by the influence of sex hormones on the inflammatory processes induced by OSA-related intermittent hypoxia (IH). ${ }^{10,11}$

This sleep disorder is caused by the loss of upper airway dilating muscle activity with repeated pharyngeal collapse, inducing apnea, oxygen saturation fall, and increase in partial pressure of carbon dioxide in arterial blood. ${ }^{12}$ To restore pharyngeal patency, patients have recurrent arousals from sleep, which induce sleep fragmentation that in turn leads to poor sleep quality, daytime sleepiness, and altered quality of life. Moreover, the chronic cycles of desaturation-reoxygenation induce oxidative stress and the production of reactive oxygen species (ROS). ${ }^{13}$ The increase in ROS level causes an increase in cell adhesion processes, ${ }^{14}$ activation of leukocytes, ${ }^{15}$ and inflammatory processes. ${ }^{16}$ Finally, hypoxemia activates the sympathetic nervous system by increasing peripheral chemoreflex sensitivity ${ }^{17,18}$ that plays a critical role in ventilatory and circulatory adaptation to chronic intermittent hypoxia (CIH). The interaction between the rise in sympathetic activity and the activation of oxidative stress and inflammatory processes underlies the cardiovascular, neurocognitive, and metabolic consequences of OSA. ${ }^{19,20}$

In this review, we first focus on experimental studies using different techniques mimicking IH exposure and then the consequences of this type of hypoxia in OSA patients.

\section{Experimental studies on IH}

Considerable evidence suggests that $\mathrm{IH}$ resulting from apnea is the primary stimulus for sympathetic overactivity in animals and humans. To confirm this hypothesis, several IH protocols have been developed both in animal models and in humans to investigate mechanisms underlying altered autonomic regulation of the circulation at systemic levels. Taking into account that experimental paradigms allow the possibility to control for confounding factors, most experimental IH protocols involve several days (10-40 days) of IH exposure, that is, CIH. Differences, however, exist between studies on the exposure paradigm used, that is, the duration of each cycle of hypoxia and reoxygenation pattern, the severity of hypoxia in each cycle, the rate (minutes vs hours vs years) of exposure, overall affecting the consequences of $\mathrm{IH}^{21,22}$ and explaining what we can define as the "beneficial" or the "deleterious" effect of IH. ${ }^{21}$

\section{Beneficial or protective effects}

Several experimental studies have reported that animals subjected to paradigms of acute $\mathrm{IH}$ become more resistant to damage related to exposure to severe hypoxia. Mice treated with acute and brief episodes of IH lasting for several hours and/or days with mild hypoxia ( $<12 \%$ of fraction of inspired oxygen $\left[\mathrm{FiO}_{2}\right]$ ) survived longer when exposed to severe $\mathrm{IH}$ characterized by cycles of desaturation-reoxygenation lasting a few seconds to minutes, being chronic if lasting weeks to months and associated with mild-to-severe hypoxia $(>12 \%$ $\left.\mathrm{FiO}_{2}\right) .{ }^{21}$ Using the low-frequency, acute and mild hypoxia paradigm, the organism will develop protective and adaptive mechanisms at the cellular, tissue, and organ levels to prevent pulmonary, ${ }^{23}$ cardiac, ${ }^{24}$ and cerebral damage. ${ }^{25}$ The principal goal of this type of $\mathrm{IH}$ is to define the characteristics of the $\mathrm{IH}$ model inducing protective and therapeutic effects in contrast to models having deleterious effects. ${ }^{26}$ The protective effect of IH is based on several mechanisms inducing a positive adaptation of the human body to hypoxia stimuli. ${ }^{21,27}$ Four mechanisms play a role in this adaptation: (i) preconditioning effects, (ii) concomitant exercise training, (iii) long-term facilitation, and (iv) cardio- and neurovascular protection. Preconditioning is a procedure by which potentially deleterious stimuli are applied near and/or below the threshold of damage to the organism. Mice exposed for a short period of just once a day survived longer than mice exposed to long and severe hypoxia with less cellular and tissue injury at lung, cerebral, and myocardium levels. ${ }^{14,28}$ After this procedure, tissues and organs can develop resistance or tolerance to the same noxious stimuli preventing or reducing the injury of $\mathrm{IH} .^{17}$ Moreover, interval exercise training in hypoxic condition promotes the induction of erythropoietin, improving the aerobic performance capacity in athletes. ${ }^{29}$ Another interesting mechanism is the long-term facilitation process that activates the expression of hypoxia-sensitive growth-tropic factors within several organs and tissues with an effect on plasticity. A short-term exposure, that is, three to ten short IH lasting for 1-2 hours/day, elicits respiratory motor plasticity, thus increasing the strength of respiratory muscle contraction and breathing, a phenomenon called long term facilitation, ${ }^{30}$ that confers neuroprotection and neuroplasticity at the lung level. Furthermore, the short hypoxia paradigm upregulates hypoxia-sensitive growth-tropic factors within respiratory motor neurons, including hypoglossal and phrenic motor output with consequent increase in phrenic, hypoglossal, or carotid sinus nerve discharges in animals ${ }^{31}$ and humans. ${ }^{32}$ This type of IH enhances the functions and number of endothelial progenitor cells promoting angiogenesis and development of coronary vessels. ${ }^{33,34}$ Moreover, conditioning exposure to a short time (5-10 minutes, 10\% of hypoxia, five to eight times/ day) protects the heart against ischemia perfusion injury by improving contractile function ${ }^{35}$ and promoting higher resistance to arrhythmias and cell death by increasing myocardial 
vascular bed, higher coronary blood flow, and expression of antioxidant proteins induced by $\mathrm{IH}^{36}$ At the cerebral level, we know that apnea of prematurity (AOP) is a risk factor for neurodevelopment disorders in children ${ }^{37}$ and newborn rodents. ${ }^{38} \mathrm{~A}$ recent study showed that exposure to moderate $\mathrm{IH}\left(8 \% \mathrm{O}_{2}\right)$ with 20 hypoxic events/hour for 6 hours/day offers neuroprotection against brain lesion and cognitive dysfunction related to AOP, a model that may be beneficial in newborns with moderate AOP. ${ }^{39}$ Similar data were described in patients with stroke in whom previous transient cerebral ischemic attacks protected them from the severity of stroke outcomes. ${ }^{40}$ Moreover, in humans with spinal cord injury, ${ }^{41,42}$ acute IH in the form of small amount of sessions of brief repeated exposure ${ }^{43}$ improved physical activity and enhanced plasticity and neural regeneration driven by hypoxia-induced release of brain-derived neurotrophic factor. These data are interesting for OSA in the elderly in whom the long duration of the disease and the low severity of hypoxemia may be considered as an ischemic preconditioning, explaining the lack of sleepiness ${ }^{44}$ and the lower morbidity and mortality. ${ }^{45,46}$

\section{Deleterious effects of $\mathrm{CIH}$ : the OSA model}

The core effect leading to OSA is susceptibility of upper airway to collapse during sleep, related both to anatomical aspects and by neural control of airway dilator muscles. During sleep, the recurrent complete (apnea) or partial (hypopnea) collapse of the upper airway induces IH and sleep fragmentation. The length of apnea-hypopnea and the length and the depth of recurrent dip in oxygen saturation influence the appearance and the severity of diurnal consequences at the cardiovascular, cerebral, and metabolic levels. Although individual susceptibility and sleep fragmentation may contribute to OSA consequences, the majority of experimental studies in animals and humans consider $\mathrm{CIH}$ the major factor acting on pulmonary, cardiac, vascular, and cerebral dysfunction in OSA. ${ }^{47}$ When $\mathrm{IH}$ is at high frequency, chronic and mild-to-severe $\left(>12 \% \mathrm{FIO}_{2}\right)$ "maladaptation" occurs, explaining the clinical consequences of OSA (Figure 1). Several animal and human paradigms have been developed to understand the deleterious effect of IH in OSA patients and the most frequent models are the following: (1) spontaneous models, (2) surgical/mechanical models, and (3) IH exposure models. ${ }^{48}$

\section{Spontaneous animal models}

The English bulldog model was the first animal spontaneous model of OSA because the dogs have a large soft palate, a narrow oropharynx, and a spontaneous tendency to snore. ${ }^{49}$ They have both central and obstructive respiratory events with worsening in rapid eye movements sleep and increasing obesity risk. In Yucatan miniature pigs,${ }^{50}$ two obese pigs had OSA and one of these had central sleep apnea. In obese Zucker rats, Brennick et $\mathrm{al}^{51}$ found small airway

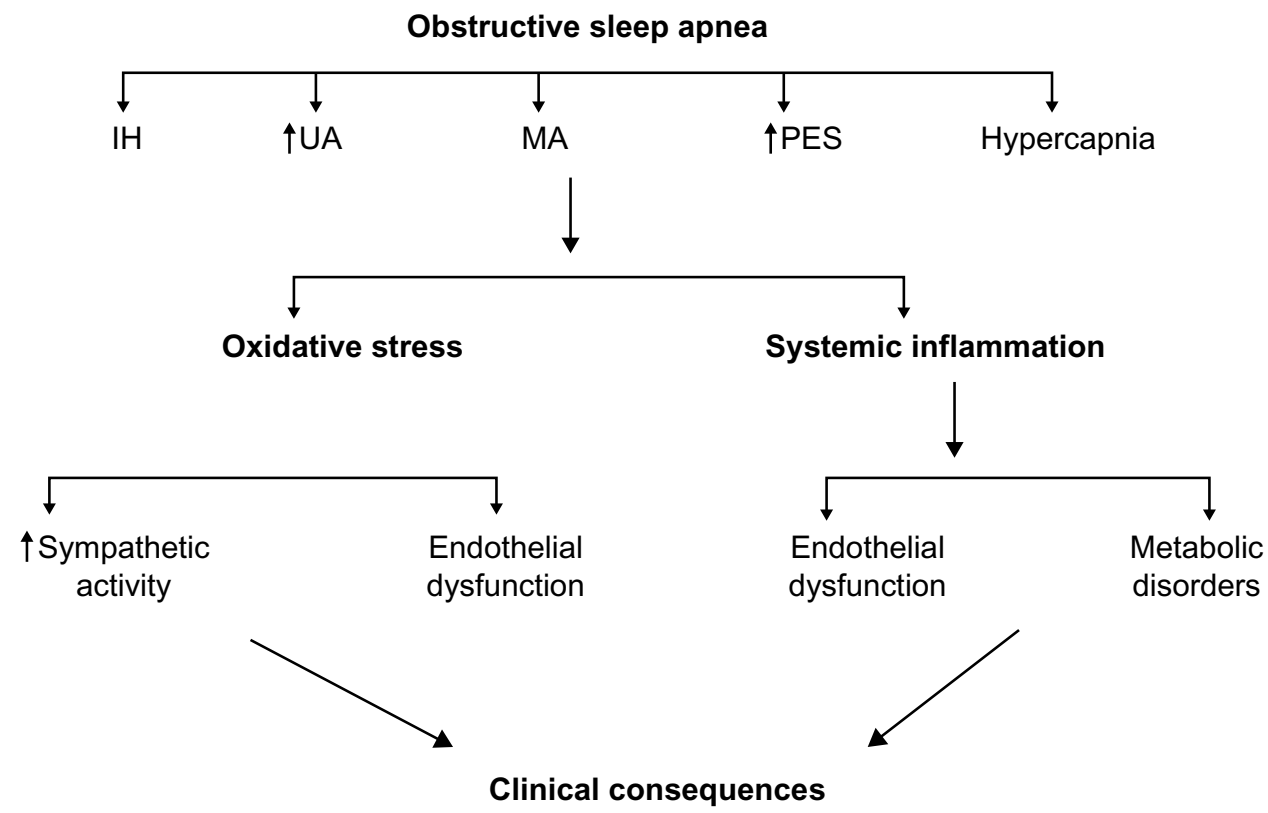

Figure I Schematic diagram showing the mechanisms leading to clinical consequences of obstructive sleep apnea.

Notes: During OSA, intermittent cycles of a fall in oxygen saturation and reoxygenation, and a rise in UA and esophageal pressure, MA, and hypercapnia occur. As a consequence, oxidative stress and systemic inflammation take place, inducing an increase in sympathetic tonus, endothelial dysfunction, and metabolic alteration, overall implicated in the majority of OSA consequences.

Abbreviations: OSA, obstructive sleep apnea; UA, pharyngeal resistance; MA, microarousal; IH, intermittent hypoxia; PES, esophageal pressure. 
cross-sectional areas during inspiration due to fat infiltration in the tongue similar to those found in OSA patients. Farré et $\mathrm{al}^{52}$ developed two versions of airway obstruction in rats, one with tracheostomy and a second one inducing airway occlusion by an external valve. Overall, these models have been used predominantly to study upper airway anatomy and physiology, including assessment of different medications. ${ }^{53}$ Interestingly, a recent paper illustrated that aged rats have reduced susceptibility to chronic IH explained by structural remodeling, which improves hypoxic tolerance in upper airway muscles that compensate for the age-related propensity for airway collapse in aged animals. ${ }^{54}$ This could explain the different phenotype of elderly OSA, showing stability or reduction of severity of the AHI. ${ }^{43}$

\section{Surgical/mechanical animal models}

OSA may be experimentally induced in several experimental models that allow researchers to modulate the occurrence of apneas, their severity, and their consequences. These studies used tracheotomy with intermittently occluded endotracheal tubes made in dogs, ${ }^{55-57}$ lambs, baboons, ${ }^{58}$ pigs,${ }^{59}$ and rats. ${ }^{60,61}$ In these models, a computer generates a period of upper airway obstruction by closing a valve in the tracheotomy. At arousal from sleep, the valve would be open, removing the pharyngeal collapse. These models more closely mimic the effect of OSA in humans, since they allow analysis of the factors implicated in OSA, including arousal from sleep, negative intrathoracic pressure, apnea length, and oxygen desaturation.

\section{IH models}

The models previously described are labor intensive and are limited by the number and size of the animal studies. In addition, results may be affected by the animals stress and the need to adapt them to the experimental condition. To limit the invasive aspect of these experimental models, the most commonly used paradigm in rat models is the induction of IH-reoxygenation by rapid delivery of a hypoxic mixture to an airtight chamber followed by flushing of the camera with normoxic room air. Rodents are exposed to periods of hypoxia of a fixed duration in the diurnal period when the animals slept and to sustained normoxia during the night that reflected the wake period for the rats. This noninvasive rodent model has the advantage of better understanding the consequences of this type of hypoxia at the cellular, tissue, and organ levels and to examine the effect of different severities of hypoxia. Since IH elicits divergent responses that are dependent on the setting of the exposure, the most common technique reduces the ambient cage oxygen to $5 \%-10 \%$ for 30 seconds to 1 minute, which results in an $\mathrm{SaO}_{2}$ ranging from $60 \%$ to $80 \%$ higher cycle frequency from seconds to a few minutes and restriction to sleep or rest. This model better mimics the cyclic oscillation of desaturations in $\mathrm{OSA}^{62}$ and explains the clinical aspect of this sleep disorder, such as hypertension (HT), ${ }^{63}$ accelerated atherosclerosis, ${ }^{64}$ brain cognitive dysfunction, ${ }^{65}$ and metabolic alterations. ${ }^{22}$ We have, however, to keep in mind that $\mathrm{IH}$ models did not reproduce all the physiological changes occurring in OSA patients, such as respiratory efforts and the hypercapnia occurring during upper airway obstruction, two factors that did not systematically occur in the rodent model. Finally, IH models induce severe hypoxemia that may be more severe than that occurring in OSA patients. Despite these limitations, this model of hypoxia-reoxygenation in mice or rats better defines the typical features of OSA, exposure to IH inducing cardiovascular consequences similar to those present in OSA patients. For this reason, in the following sections, we describe the OSA consequences in humans taking into account the data of experimental IH models.

\section{Intermittent chronic hypoxia and HT}

In this section, we describe in detail the markers and the mechanisms of HT that are the most frequent cardiovascular consequence of OSA and linearly associated with AHI and the severity of hypoxemia. ${ }^{55,66}$ It is well described that cardiovascular homeostasis depends on peripheral feedback information that initiates reflex adjustments in response to environmental changes (Figure 2). The carotid bodies located at the bifurcation of the common carotid arteries are the sensory organs detecting continuous changes in oxygen levels in arterial blood and eliciting cardiovascular changes to ensure adequate oxygen supply in hypoxemic conditions. These oxygen-sensitive cells are also located on aortic bodies located in the aortic arch and at the thoraco-abdominal level, ${ }^{67}$ all regulating the cardiorespiratory function during hypoxia. ${ }^{68}$ These peripheral sensory areas release neurotransmitters in response to hypoxia, activating different nerves that project to the neurons of the nucleus tractus solitaris (NTS) in the brainstem. ${ }^{69}$ From the NTS, the chemoreceptor inputs are transmitted to other brain regions engaged in autonomic control with activation of the sympathetic arm. Therefore, enhanced carotid body and aortic body responsiveness to hypoxia may be considered as the most important receptors for detecting blood oxygen and activating reflexes during IH. ${ }^{70}$ When these peripheral chemoreceptors and chemoreflexes are activated by $\mathrm{IH}$, a rise in the sympathetic nervous 


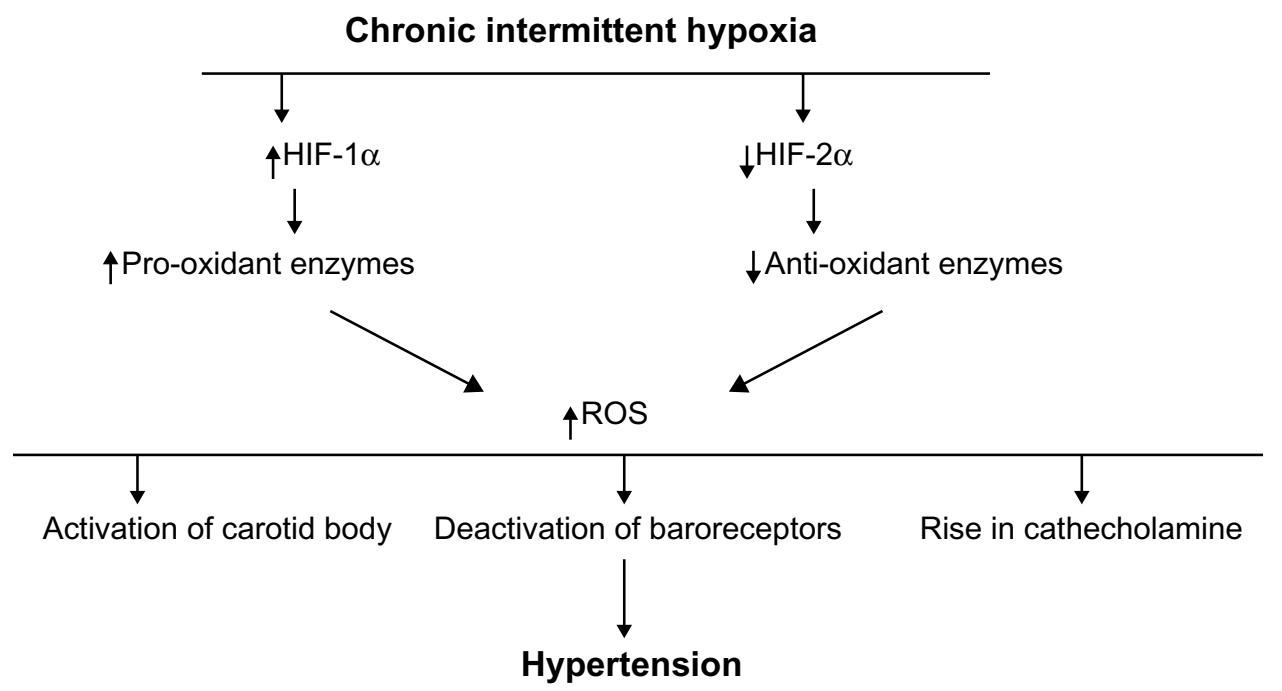

Figure 2 Schematic presentation of the hypothesized pathways by which intermittent hypoxia leads to hypertension.

Notes: Chronic intermittent hypoxia increases the HIF-I with a rise of the HIF-I $\alpha$ subunit that activates pro-oxidant enzymes and a decrease of HIF-2 $\alpha$, inducing a fall in antioxidant enzymes. These changes induce a rise of ROS implicated in the activation of peripheral chemoreceptors, the deactivation of baroreceptors, and the activation of adrenal medullary activity, all factors promoting increase of sympathetic activation and hypertension.

Abbreviations: HIF, hypoxia inducible factor; ROS, reactive oxygen species.

system occurs, ${ }^{7,71}$ contributing to the rise of blood pressure (BP) and HT. This hypothesis is supported by the observation that OSA subjects having ablation of carotid body did not develop HT. ${ }^{72}$ Moreover, in a series of experiments, Fletcher et $\mathrm{al}^{73}$ were the first to show that rats exposed to $\mathrm{IH}$ for 3 weeks developed HT prevented by surgical denervation of peripheral chemoreceptors. ${ }^{73}$ Furthermore, adrenal demedullation $^{74}$ and chemical sympathectomy using inhibition by 6-hydroxydopamine prevented a rise in $\mathrm{BP}$ response to IH. ${ }^{75}$ Additional studies in rats,${ }^{76}$ cats,,${ }^{77}$ and mice ${ }^{78}$ confirmed the key role of peripheral chemoreceptors on sympathetic activation and HT.

To explain which markers and mechanisms are implicated in OSA HT (Figure 2), we have to keep in mind that just a single session of IH exposure lasting just seconds or minutes, that is, acute $\mathrm{IH}$, is already able to activate peripheral chemoreceptors. ${ }^{79}$ While acute IH depends just on the sensitivity of peripheral arterial chemoreceptors to hypoxic stimulus, in contrast, $\mathrm{CIH}$ activates pro-inflammatory molecules, enhances cellular generation of ROS and reactive nitrogen species that are considered markers of oxidative stress, ${ }^{23,80}$ inducing a long-lasting stimulation of arterial chemoreflexes, and elevates chronic sympathetic nerve activation. ${ }^{49,81}$ The enhanced cellular generation of ROS and reactive nitrogen species contributes to the general inflammation by activation of inflammatory processes and cytokine/chemokine production. In addition, $\mathrm{CIH}$ triggers the activation of proinflammatory transcription factors such as hypoxia-inducible factor (HIF)-1 $\alpha^{82}$ and nuclear factor that determine an activa- tion of some genetic factors and an induction of adhesion molecules, tumor necrosis factor- $\alpha$, interleukin- 6 , chemokines, C-reactive protein, cyclooxygenase, and thromboxane synthase, the latter increasing atherosclerotic risk. In addition to production of pro-inflammatory molecules, IH increases the levels of angiotensin II and endothelin I, both activating chemosensory areas. Thus, it could be suggested that the augmented sympathetic activity resulting from increased carotid body chemoreflexes mediated HIF- $\alpha$ dysregulation and oxidative stress, affecting not only the carotid body chemoreflex pathways but also the adrenal medulla. The last area may increase catecholamine secretion and thus arterial hypertension. ${ }^{83,84}$

In addition, studies in humans demonstrated that OSA patients had reduced baroreflex sensitivity, as suggested by heart rate and vascular resistance response to activation of baroreceptors ${ }^{85,86}$ and the reversal after continuous positive airway pressure treatment. Although speculative, Prabhakar et a ${ }^{18}$ suggested that $\mathrm{CIH}$ upregulates chemoreceptors and downregulates baroreceptor activity. The hypoxic drive stimulates carotid baroreceptors and increases the level of endothelin 1, a strong vasoconstrictor peptide that reduces baroreceptor sensitivity and attenuates baroreflex responses. The fall in baroreceptor activity and the augmented chemoreflex both enhance sympathetic activity, which seems to be determinant in the maintenance of $\mathrm{IH}$.

In addition to peripheral pathways, central factors may contribute to sympathetic overactivity in $\mathrm{IH}$. We know that the paraventricular nucleus of hypothalamus is a critical factor 
in setting autonomic tonus and in particular parasympathetic tonus, ${ }^{87}$ and the neurons of the NTS ${ }^{88}$ increase in the neuronal response to $\mathrm{IH}$. These two brain areas activate peripheral chemoreceptors and deactivate baroreflex sensitivity, favoring an additional rise of the sympathetic tonus and a fall of parasympathetic tone. The altered balances between cardioprotective parasympathetic activity and enhanced sympathetic tonus result in tachycardia, decreased baroreflex sensitivity, and a rise in BP and cardiovascular risk. ${ }^{89}$ These consequences are explained by the effect of GABAergic mechanisms that exert an inhibitory effect on parasympathetic cardiac vagal neurons, ${ }^{90}$ and orexin-A acting on parasympathetic control of the heart rate. ${ }^{91}$ The effect of decreased baroreceptor activity and plasma levels of orexin- $\mathrm{A}^{92}$ and its consequences on BP control has also been demonstrated in OSA patients. ${ }^{93}$

Two interesting points of discussion have been proposed more recently on the link between HT and IH. The first is if preconditioning to intermittent or sustained hypoxia would affect cardiovascular changes occurring after a sustained IH or CHI. According to Perim et al, ${ }^{90}$ previous exposure to $\mathrm{CIH}$ or sustained hypoxia did not facilitate or prevent cardiovascular changes produced by chronic IH. Second, although several studies have stressed the importance of peripheral chemoreceptors for hypertensive risk in models of IH, an enhanced sympathetic outflow may also be derived on alteration of the link between respiratory networks and sympathetic activation. As shown by the results of Zoccal in rat models, ${ }^{91}$ expiratory neurons located in the parafacial respiratory group might be activated by central chemoreflexes inducing an increase of expiratory parafacial respiratory group neurons that drive sympathetic overactivity in rats exposed to CIH. These results open discussion on the role of the interaction between expiratory activity and sympathetic activity in occurrence and persistence of arterial HT in animals exposed to $\mathrm{CIH}$.

\section{Intermittent chronic hypoxia and vascular and endothelial remodeling}

Systemic inflammation, ${ }^{94-96}$ oxidative stress, ${ }^{34}$ endothelial dysfunction, ${ }^{97}$ and increased sympathetic activity induce hemorheologic alterations with increased cell adhesion molecules, endothelial cell dysfunction, thrombotic factor activation, procoagulant activity, ${ }^{98}$ and vascular remodeling, all factors contributing to atherosclerotic risk ${ }^{99}$ and consequent cardiovascular morbidity and mortality. Animal studies suggest that reduction of endothelial-dependent vasodilatation is the most important precursor for atherosclerosis, related to increased oxidative stress with reduced levels of nitric oxide (NO). Rats exposed to $\mathrm{CIH}$ exhibit a reduced vasodilatation in response to infusion of acetylcholine and reduced vasoconstriction following NO synthase inhibition. ${ }^{100}$ Thus, increased vascular inflammation and lipid peroxidation ${ }^{101}$ in response to oxidative stress play a key role on such endothelial dysfunction.

\section{Intermittent chronic hypoxia and metabolic consequences}

Chronic exposure to IH as present in OSA may contribute to metabolic consequences including type 2 diabetes, insulin resistance, dyslipidemia, and obesity. ${ }^{102}$ The most evident factor linking metabolic consequences and $\mathrm{IH}$ is sympathetic overactivity $^{38}$ that increases catecholamine levels, which produces hyperglycemia and hyperinsulinemia and promotes insulin resistance. ${ }^{103}$ Moreover, activation of the sympathetic system may stimulate the release of adipocyte-derived inflammatory mediators such as interleukin-6, tumor necrosis factor- $\alpha$, and leptin, factors which can induce lipolysis and release of free fatty acids from adipose tissue; with the latter impairing glucose uptake by the tissues contributing to hyperglycemia and hyperinsulinemia. ${ }^{104}$ This hypothesis has been partially confirmed by Polotsky et al, ${ }^{101}$ showing that obese mice intermittently exposed for 12 weeks to $\mathrm{CIH}$ developed a time-dependent increase in fasting serum insulin levels and worsening of glucose tolerance, underlying the increase in insulin resistance.

\section{Intermittent chronic hypoxia and cognition}

At the cerebral level, OSA causes neuropsychological effects including impaired memory, attention, and executive dysfunction, all of which are compatible with morphological or functional alteration in the cerebral areas implicated on cognitive performances. Despite that sleep fragmentation may contribute to cognitive dysfunction, experimental and clinical studies support the hypothesis that $\mathrm{IH}$ alone plays a key role in cognitive dysfunction in OSA. Exposure to experimentally induced IH in rodent models is associated with time-related neurodegenerative changes, including alteration in brain regions and in neurotransmitter systems involved in learning, attention, and memory. ${ }^{106,107}$ There are several rodent IH models showing cellular damage of the CA1 area of the hippocampus that is important in learning and memory, and which are considered as hippocampal-dependent. ${ }^{108,109}$ The mechanisms by which IH induces hippocampus dysfunction are multiple, involving glutamate release, growth-tropic factors, ${ }^{110}$ chronic excitotoxity, diminished apolipoprotein E, 
and NO reduction. The most evident proposed explanation is oxidative stress ${ }^{111}$ inducing inflammation and apoptosis. ${ }^{112}$

In humans with OSA, Beebe and Gozal proposed the "prefrontal model" that is derived by the interplay of apnearelated sleep fragmentation and $\mathrm{IH} .{ }^{109}$ According to this model, OSA sleep fragmentation and IH alter the efficacy of the sleep-related restorative process and cellular, chemical homeostasis and neuronal viability, particularly in cerebral areas. The proposed prefrontal dysfunction modifies the recruitment of primary cognitive abilities, resulting in a maladaptive behavior.

\section{Intermittent chronic hypoxia and cancer risk}

In recent years, the adverse role of OSA in cancer incidence has been found in OSA patients and confirmed by animal IH models with cancer. ${ }^{112-115} \mathrm{Cyclic} \mathrm{IH}$ acts on redox-sensitive transcription factors such as HIF-1, AP-1, metalloprotease, tumor-associated macrophages, and vascular endothelial growth factor that play a key role in angiogenesis, genetic modifications, different stages of cell differentiation and proliferation, and formation of cancer-related stem cells. ${ }^{114,116}$ A recent paper ${ }^{115}$ suggested that OSA might enhance proliferative and invasive properties of solid tumors by increasing sympathetic tonus and alteration of immune function induced by IH which are implicated in cancer processes. These results have been confirmed in two epidemiological studies from the Wisconsin cohort ${ }^{112}$ and the Spanish Sleep Networks, ${ }^{116}$ both showing an increased risk of cancer in severe OSA patients related to $\mathrm{IH}$, facilitating carcinogenesis through anti-apoptosis mechanisms.

\section{Conclusion and perspectives}

In this review, we have highlighted studies addressing the mechanisms by which OSA causes persistent cardiovascular, metabolic, and cognitive consequences as well as increased cancer risk. Animal and clinical data support a specific role for IH in promoting changes at molecular, cellular, and tissue levels that explain the OSA consequences. The association of OSA to vascular, metabolic, genetic, and cognitive consequences may be explained by the interplay of several pathways including sympathetic overactivity, oxidative stress, pro-inflammation processes, and sleep fragmentation. The actual acknowledgment of OSA consequences derives essentially from experimental IH models that provide a more specific insight on the mechanisms underlying the effects of IH. The use of animal models is essential for researchers and clinicians to better understand OSA pathophysiology and develop therapeutic interventions based also on the "beneficial effects" of IH in cardiac, cerebral, and muscular human pathologies. We have, however, to keep in mind that OSA varies from patient to patient, suggesting a specific disease phenotype that should be considered in order to optimize future therapeutic strategies and outcome.

\section{Disclosure}

The authors report no conflicts of interest in this work.

\section{References}

1. Young T, Palta M, Dempsey J, Skatrud Weber S, Badr S. The occurrence of sleep-disordered breathing among middle-aged adults. $N$ Engl J Med. 1993;328(17):1230-1235.

2. Bixler E, Vgontzas A, Ten Have T, Tyson K, Kales A. Effect of age on sleep apnea in men. Am J Respir Crit Care Med. 1998;157(1):144-148.

3. Bixler E, Vgontzas A, Lin H, et al. Prevalence of sleep-disordered breathing in women. Am J Respir Crit Care Med. 2001;163(3):608-613.

4. Duran J, Esnaola S, Rubio R, Iztueta A. Obstructive sleep apneahypopnea and related clinical features in a population-based sample of subjects aged 30-70 yr. Am J Respir Crit Care Med. 2001;163(3): 685-689.

5. Quan SF, Howard BV, Iber C, et al. The Sleep Heart Health Study: design, rationale and methods. Sleep. 1997;20(12):1077-1085.

6. Popovic RM, White DP. Upper airway muscle activity in normal women: influence of hormonal status. J Appl Physiol. 1998;84(3):1055-1062.

7. Schwab RJ. Sex differences and sleep apnea. Thorax. 1999;54(4): 284-285.

8. Aubrecht TG, Jenkins R, Magalang UJ, Nelson RJ. Influence of gonadal hormones on the behavioral effects of intermittent hypoxia in mice. Am J Physiol Regul Integr Comp Physiol. 2015;308(6):R489-R499.

9. Torres M, Palomer X, Montserrat JM, Vaquez-Carrera M, Farré R. Effect of ovariectomy on inflammation induced by intermittent hypoxia in a house model of sleep apnea. Respir Physiol Neurobiol. 2014;202(1):71-74.

10. Ancoli-Israel S, Kripke D, Klauber M, Mason W, Fell R, Kaplan O. Sleep-disordered breathing in community-dwelling elderly. Sleep. 1991;14(6):486-495.

11. Young T, Shahar E, Nieto FJ, et al. Predictors of sleep-disordered breathing in community-dwelling adults. The Sleep Heart Health Study. Arch Intern Med. 2002;162(8):893-900.

12. Young T, Peppard PE, Gottlieb DJ. Epidemiology of obstructive sleep apnea: a population health perspective. Am J Respir Crit Care Med. 2002;165(9):1217-1239.

13. Lavie P. Obstructive sleep apnea-an oxidative stress disorder. Sleep Med Rev. 2003;7(1):35-51.

14. Baguet JP, Barone-Rochette G, Tamisier R, Levy P, Pepin JL. Mechanisms of cardiac dysfunction in obstructive sleep apnea. Nat Rev Cardiol. 2012;9(12):679-688

15. Schulz R, Mahamoudi S, Hattar K, et al. Enhanced release of peroxide from polymorphonuclear neutrophils in obstructive sleep apnea. Impact of continuous positive airway pressure therapy. Am J Respir Crit Care. 2000;162(2 Pt 1):566-570.

16. Garvey JF, Taylor CT, McNicholas WT. Cardiovascular disease in obstructive sleep apnea: the role of intermittent hypoxia and inflammation. Eur Respir J. 2009;33(5):1195-1205.

17. Peng YJ, Overholt JL, Kline D, Kumar GK, Prabhakar NR. Induction of long sensory long-term facilitation in carotid body by intermittent hypoxia: implications for recurrent apneas. PNAS. 2003;100(17):10073-10078.

18. Prabhakar NR, Peng YJ, Kumar GK, Nanduri J. Peripheral chemoreception and arterial pressure responses to intermittent hypoxia. Compr Physiol. 2015;5(2):561-577. 
19. Lévy P, Tamisier R, Minville C, Launois S, Pépin JL. Sleep apnoea syndrome in 2011: current concepts and future conditions. Eur Respir Rev. 2011;20(121):134-146.

20. Ayas NT, Hirsch AA, Laher I, et al. New frontiers in obstructive sleep apnea. Clin Sci. 2014;127(4):209-216.

21. Almendros I, Wang Y, Gozal D. The polymorphic and contradictory aspects of intermittent hypoxia. Am J Physiol Lung Cell Mol Physiol. 2014;307(2):129-140.

22. Reinke C, Stevans-Fonti S, Drager LF, Skin MK, Polotsky VY. Effects of different acute hypoxic regimens on tissue oxygen profiles and metabolic outcomes. J Appl Physiol. 2011;111(3):1881-1890.

23. Zhang SX, Miller JJ, Gozal D, Wang Y. Whole-body hypoxic conditioning protect mice against acute hypoxia by improving lung function. J Appl Physiol. 2004;96(1):392-397.

24. Beguin PC, Joyeux-Faure M, Godin-Ribout D, Levy P, Ribout C. Acute intermittent hypoxia improves rat myocardium tolerance to ischemia. J Appl Physiol. 2005;99(3):1064-1069.

25. Tsai YW, Yang YR, Wang PS, Wang RY. Intermittent hypoxia after transient focal ischemia induces hippocampal neurogenesis and c-Fos expression and reverse spatial memory deficits in rats. PLoS One. 2011;6:e24001.

26. Navarrete-Opazio A, Mitchell GS. Therapeutic potential of intermittent hypoxia: a matter of dose. Am J Physiol Regular Integr Comp Physiol. 2014;307(10):R1181-R1197.

27. Verges S, Chacaroun S, Godin-Ribout D, Baillieul S. Hypoxic conditioning as a new therapeutic modality. Front Pediatr. 2015;22(3):58.

28. Bourdier G, Flore P, Sanchez H, Pepin JL, Belaidi E, Arnaud C. High-intensity training reduces intermittent hypoxia-induced ER stress and myocardial infarct site. Am J Physiol Heart Circ Physiol. 2015;310(2):279-289.

29. Rodriguez FA, Casas H, Casas M, et al. Intermittent hypobaric hypoxia stimulates erythropoiesis and improves aerobic capacity. Med Sci Sports Exerc. 1999;31(2):264-268.

30. Dale EA, Ben MF, Mitchell GS. Unexpected benefits of intermittent hypoxia: enhanced respiratory and respiratory motor function. Physiology. 2014;29(1):39-48.

31. Mahamed S, Mitchell GS. Is there a link between intermittent hypoxiainduced respiratory plasticity and obstructive sleep apnea. Exp Physiol. 2007;92(1):27-37.

32. Xing T, Fong AY, Bautista TG, Pilowskiy PM. Acute intermittent hypoxia induces neural plasticity in respiratory motor control. Clin Exp Pharmacol Physiol. 2013;40(9):602-609.

33. Lavie L. Oxidative stress in obstructive sleep apnea and intermittent hypoxia-revisited-the bad ugly and good: implications in the heart and the brain. Sleep Med Rev. 2014;20:27-45.

34. Shizukuda Y, Mallet RT, Lee SC, Reimer KA. Hypoxic conditioning of ischaemic canine myocardium. Cardiovasc Res. 1992;26(5):1124-1136.

35. Manukhina EB, Bellkina M Trekhina OL, et al. Normobaric, intermittent hypoxia conditioning is cardio- and vasoprotective in rats. Exp Biol Med. 2013;238(2):1413-1420.

36. Zhuang J, Zhou Z. Protective effects of intermittent hypoxic adaptation on myocardium and its mechanisms. Biol Signals Recept. 1999;8(4-5):316-322.

37. Zhao J, Gonzalez F, Mu D. Apnea of prematurity: from cause to treatment. Eur J Pediatr. 2011:170(9):1097-1105.

38. Gozal D, Daniel JM, Dohanich GP. Behavioral and anatomical correlates of chronic episodic hypoxia during sleep in the rat. $J$ Neurosci. 2001;21(7):2442-2450.

39. Bouslama M, Biasette HA, Ramanatsoa N, et al. Protective effect of intermittent hypoxia on brain and memory in a mouse model of apnea of prematurity. Front Physiol. 2015;6:313.

40. Moncayo J, de Freitas GR, Bogousslavky J, Altieri M, Van Melle G. Do transient ischemic attacks have a neuroprotective effect? Neurology. 2000;54(11):2089-2094.

41. Hayes HB, Jayaraman A, Mitchell GS, Rimer WZ, Trumbower RD. Daily intermittent hypoxia enhances walking after chronic spinal injury: a randomized trial. Neurology. 2014;82(2):104-113.
42. Astorino TA, Harness ET, White AC. Efficacy of acute intermittent hypoxia on physical function and health status in humans with spinal cord injury: a brief review. Neural Plast. Epub Jun 8, 2015.

43. Trumbower RD, Jayaraman GS, Mitchell GS, Rymer WZ. Exposure to acute intermittent hypoxia augments somatic motor function in human with incomplete spinal cord injury. Neurorehabil Neural Repair. 2012;26(2):163-172.

44. Sforza E, Pichot V, Martin MS, Barthélémy JC, Roche F. Prevalence and determinants of subjective sleepiness in healthy elderly with unrecognized obstructive sleep apnea. Sleep Med. 2015;16(8):981-986.

45. Lavie L, Lavie P. Ischemic preconditioning as a possible explanation for the age decline relative mortality in sleep apnea. Med Hypotheses. 2006;66(6):1069-1073.

46. Sforza E, Gauthier M, Crawford-Achour E, et al. A 3-year longitudinal study of sleep disordered breathing in the elderly. Eur Respir J. 2012;40(3):665-672.

47. Dewan NA, Nieto FJ, Somers VK. Intermittent hypoxemia and OSA: implication for comorbidities. Chest. 2015;147(1):266-274.

48. Dematteis M, Godin-Ribout D, Arnaud C, et al. Cardiovascular consequences of sleep-disordered breathing: contribution of animal models to understanding of the human disease. ILAR J. 2009;50(3):262-281.

49. Hendricks JC, Kline LR, Kovalski RJ, O’Brien JA, Morrison AR, Pack AI. The English bulldog: a natural model of sleep-disordered breathing. J Appl Physiol. 1987;63(4):1344-1350.

50. Lonergan RP, Ware JC, Atkinson RL, Winter WC, Suratt PM. Sleep apnea in obese miniature pigs. J Appl Physiol. 1998;84(2):531-536.

51. Brennick MJ, Pichup S, Cater JR, Kuna ST. Phasic respiratory pharyngeal mechanisms by magnetic resonance imaging in lean and obese Zucker rats. J Am Respir Crit Care Med. 2006;173(9):1031-1037.

52. Farré R, Nacher M, Serrano-Mollar A, et al. Rat model of chronic recurrent airway obstructions to study the sleep apnea syndrome. Sleep. 2007;30(7):930-933.

53. Veasey SC, Chachkes CJ, Fenik P, Hendricks JC. The effect of ondansetron on sleep-disordered breathing in the English bulldog. Sleep. 2001;24(2):55-60.

54. Skelly JR, Edge D, Schortt CM, Jones JF, Bradford A, O'Halloran KD. Respiratory control and sternohyoid muscle structure and function in aged male rats: decreased susceptibility to chronic intermittent hypoxia. Respir Physiol Neurobiol. 2012;180(2-3):175-182.

55. Brooks D, Horner RL, Kozar LF, Render-Teixera CL, Phillipson EA. Obstructive sleep apnea cause as a cause of systemic hypertension: evidence from a canine model. J Clin Invest. 1997;99(1):106-109.

56. Kimoff RJ, Makino H, Horner RL, et al. Ventilatory and arousal responses to hypoxia and hypercapnia in a canine model of obstructive sleep apnea. Am J Respir Crit Care Med. 1997;156(3 Pt 1):896-894.

57. Kimoff RJ, Brooks D, Horner RL, et al. Canine model of obstructive sleep apnea: model description and preliminary application. $J$ Appl Physiol. 1994;76(4):1810-1817.

58. White SG, Fletcher EC, Miller CC. Acute systemic blood pressure elevation in obstructive and nonobstructive breath holds in primates. J Appl Physiol. 1995;79(1):324-330.

59. Chen L, Scharf SM. Effects of aortic nerve on hemodynamic response to obstructive apnea in sedated pigs. J Appl Physiol. 2000;89(4):1455-1461.

60. Fletcher EC, Lesske J, Qian W, Miller CC. Repetitive episodic hypoxia causes diurnal elevation of blood pressure in rats. Hypertension. 1992;19(6 Pt 11):555-561.

61. Nacher M, Serrano-Mollar A, Farré R, Panes J, Segui J, Montserrat JM. Recurrent obstructive sleep apneas trigger early systemic inflammation in a rat model of sleep apnea. Respir Physiol Neurobiol. 2007;155(1):93-96.

62. Dumitrascu R, Heitmann J, Seeger W, Weissmann N, Schulz R. Obstructive sleep apnea, oxidative stress and cardiovascular disease: lessons from animal studies. Oxid Med Cell Longev. 2013;4:1-7.

63. Peppard PE, Young T, Palta M, Skatrud J. Prospective study of association between sleep-disordered breathing and hypertension. $N$ Engl J Med. 2000;342(19):1378-1384. 
64. Drager LF, Yao Q, Hernandez KL, et al. Chronic intermittent hypoxia induces atherosclerosis via activation of adipose-angiopoietin-like 4 . Am J Respir Crit Care Med. 2013;188(2):240-248.

65 . Veasey $\mathrm{S}$. Insight from animal model into the cognitive consequences of adults-sleep disordered breathing. ILAR J. 2009;50(3):307-311.

66. McNicholas WT, Bonsignore MR. Management Committee of EU Cost Action B26. Sleep apnoea as an independent risk factor for cardiovascular disease: current evidence, basic mechanisms and research priorities. Eur Respir J. 2007;29(1):156-178.

67. Easton J, Howe A. The distribution of thoracic glomus tissue (aortic bodies) in the rat. Cell Tissue Res. 1983;232(2):349-356.

68. Comroe JH. The location and function of the chemoreceptor of the aorta. Am J Physiol. 1939;127(1):176-191.

69. Molkov YI, Zoccal DB, Morales DJ, Paton JF, Machado BH, Rybak IA. Intermittent hypoxia-induced sensitization of central chemoreceptors contributes to sympathetic nerve activity during late expiration in rats. J Neurophysiol. 2011;105(6):3080-3091.

70. Leuenberger UA, Brubaker D, Quraishi S, Hogeman CS, Imadojeumi VA, Gray KS. Effects of intermittent hypoxia on sympathetic activity and blood pressure in humans. Auton Neurosci. 2005;121(1-2):87-93.

71. Tamisier R, Pepin JL, Remy J, et al. 14 nights of intermittent hypoxia elevate daytime blood pressure and sympathetic activity in healthy humans. Eur Respir J. 2011;37(1):119-128.

72. Somers VK, Abboud FM. Chemoreflexes-responses, interaction and implication for sleep apnea. Sleep. 1993;16(Supp1):S30-S33.

73. Fletcher EC, Lesske J, Culman J, Miller CC, Unger T. Sympathetic denervation blocks blood pressure elevation in episodic hypoxia. Hypertension. 1992;20(5):612-619.

74. Bao G, Randhawa M, Flecther EC. Acute blood pressure elevation during repetitive hypocapnic and eucapnic hypoxia in rats. J Appl Physiol. 1997;82(4):1071-1078.

75. Flecther EC, Bao G. Influence of hypoxia, chemoreceptors and sympathetic activity in chronic hypertension in rats. In: Lenfant C, Bradly TD, Floras IS, editors. Sleep Apnea: Implication in Cardiovascular and Cerebrovascular Diseases. New York: Marcel Dekker; 2000:181-211.

76. Peng YJ, Renisson J, Prahbhakar NR. Intermittent hypoxia augments carotid body and ventilatory response to hypoxia in neonatal rat pups. J Appl Physiol. 2004;97(5):2020-2025.

77. Rey S, Del Rio R, Alcayaga J, Itturiaga R. Chronic intermittent hypoxia enhances cat chemosensory and ventilatory responses to hypoxia. J Physiol. 2004;560(Pt 2):577-586.

78. Peng YJ, Yuan G, Ramakrishan D, et al. Heterozygous HIF-1alpha deficiency impairs carotid-body-immediate systemic response and reactive oxygen species generation in mice exposed to intermittent hypoxia J Physiol. 2006;577(Pt 2):705-716.

79. Prabhakar NR. Oxygen sensing by the carotid body chemoreceptors. J Appl Physiol. 2000;88(6):2287-2295.

80. Prabhakar NR. Oxygen sensing during intermittent hypoxia: cellular and molecular mechanisms. J Appl Physiol. 2001;90(6):1986-1994.

81. Lesske J, Fletcher EC, Bao G, Unger T. Hypertension caused by chronic intermittent hypoxia-influence of chemoreceptors and sympathetic nervous system. J Hypertens. 1997;15(12 Pt 2):1593-1603.

82. Toffoli S, Roegiers A, Feron $\mathrm{O}$, et al. Intermittent hypoxia is an angiogenic inducer for endothelial cells: role of HIF-1. Angiogenesis. 2009;12(1):47-67.

83. Prabhakar NR, Kumar GK, Peng YJ. Sympatho-adrenal activation by chronic intermittent hypoxia. J Appl Physiol. 2012;113(8):1304-1310.

84. Kumar GK, Nanduri J, Peng YJ, Prabhakar NR. Neuromolecular mechanisms mediating the effects of chronic intermittent hypoxia on adrenal medulla. Respir Physiol Neurobiol. 2015;209:115-119.

85. Bonsignore MR, Parati G, Insalaco G, et al. Continuous positive airway pressure treatment improves baroreflex of heart rate during sleep in severe obstructive sleep apnea syndrome. Am J Respir Crit Care Med. 2002;166(3):279-286.

86. Cooper VL, Elliot MW, Pearson SB, Taylor CM, Mohammed MM, Hainworth R. Daytime variability of baroreflex function in patients with obstructive sleep apnoea: implication for hypertension. Exp Physiol. 2007;92(2):391-398.
87. Sharpe AL, Calderon AS, Andrade MA, Cunnigham JT, Toney GM. Chronic intermittent hypoxia increase sympathetic control of blood pressure: role of neuronal activity in the hypothalamic paraventricular nucleus. Am J Physiol Heart Circ Physiol. 2013:305(12):H1772-H1780.

88. Moreau M, Ciriello J. Chronic intermittent hypoxia induces changes in expression of synaptic proteins in the nucleus of the solitary tract. Brain Res. 2015;1622:300-307.

89. Dergacheva O, Dyavanapalli JD, Pinol RA, Mendelowitz D. Chronic intermittent hypoxia and hypercapnia inhibits the hypothalamic paraventricular nucleus neurotransmission to parasympathetic cardiac neurons in the brainstem. Hypertension. 2014;64(3):597-603.

90. Perim RR, Bonagamba LG, Machado BH. Cardiovascular and respiratory outcome of preconditioned rats submitted to chronic intermittent hypoxia. Exp Physiol. 2015;100(9):1008-1017.

91. Zoccal DB. Peripheral chemoreceptors and cardiorespiratory coupling: link to sympatho-excitation. Exp Physiol. 2015;100(2):143-148.

92. Ryan S, Taylor CT, McNicholas WT. Selective activation of inflammatory pathways by intermittent hypoxia in obstructive sleep apnea. Circulation. 2005;112(17):2660-2667.

93. Jelic S, Padeletti M, Kawut SM, et al. Inflammation, oxidative stress and repair capacity of the vascular endothelium in obstructive sleep apnea. Circulation. 2008;117(17):2270-2278.

94. De Lima FF, Mazzotti DR, Tufik S, Bittencourt L. The role of inflammatory response genes in obstructive sleep apnea syndrome: a review. Sleep Breath. 2016;20(1):331-338.

95. Gras E, Belaidi E, Briancon-Marjollet A, Pépin JL, Arnaud C, GodinRibout D. Endothelin-1 mediates intermittent hypoxia-induced inflammatory vascular remodelling through HF1-activation. J Appl Physiol (1985). 2016;120(4):437-443.

96. Tahawi Z, Orolinova N, Joshua G, Bader M, Fletcher EC. Altered vascular reactivity in arterioles of chronic intermittent hypoxic rats. J Appl Physiol. 2001;90(5):2007-2013.

97. Li J, Savranski V, Nanayakkara A, Smith PL, O’Donnell CP, Polotsky VY. Hyperlipidemia and lipid peroxidation are dependent on the severity of chronic intermittent hypoxia. J Appl Physiol. 2007;102(2):557-563.

98. Bonsignore MR, Eckel J. Metabolic aspects of obstructive sleep apnoea syndrome. Eur Respir J Rev. 2009;18(112):113-124.

99. Cheng L, Khoo MCK. Modeling the autonomic and metabolic effects of obstructive sleep apnea: a simulation study. Front Physiol. 2012;2:111.

100. Punjabi NM, Polotsky VY. Disorders of glucose metabolism in sleep apnea. J Appl Physiol. 2005;99(5):1998-2007.

101. Roy A, Parker RS. Dynamic modelling of free-fatty acid, glucose and insulin: an extended minimal model. Diabetes Technol Ther. 2006;8(6):617-626.

102. Polotsky VY, Li J, Punjabi NM,. Intermittent hypoxia increase insulin resistance in genetically obese mice. J Physiol. 2003;552(1): 253-264.

103. Gozal D, Reeves SR, Row BW, Neville JJ, Guo S, Lipton AJ. Respiratory effects of gestational intermittent hypoxia in developing rat. Am J Respir Crit Care Med. 2003;167(11):1540-1547.

104. Kheirandish L, Row BW, Li RC, Brittian KR, Gozal D. Apolipoprotein E-deficient mice exhibit increased vulnerability to intermittent hypoxiainduced spatial learning deficits. Sleep. 2005;28(11):1412-1417.

105. Ward CP, McCoy JG, McKenna JT, Connoly NP, McCarley RW, Strecker RE. Spatial learning and memory deficits following exposure of $24 \mathrm{~h}$ of sleep fragmentation or intermittent hypoxia in a rat model of obstructive sleep apnea. Brain Res. 2009;1294:128-137.

106. Nair D, Ramesh V, Li RC, Schally AV, Gozal D. Growth hormone releasing hormone $(\mathrm{GHRH})$ signaling modulates intermittent hypoxiainduce oxidative stress and cognitive decline in mouse. $J$ Neurochem. 2013;127(4):1-4

107. Row BW, Liu R, Xu W, Kheirandish L, Gozal D. Intermittent hypoxia is associated with oxidative stress and spatial learning deficits in the rat. Am J Respir Crit Care Med. 2003;167(11):1533-1548. 
108. Xu W, Chi L, Row BW, et al. Increased oxidative stress is associated with chronic intermittent hypoxia-mediated brain cortical neuronal cell apoptosis in a mouse model of sleep apnea. Neuroscience. 2004;126(2):313-323.

109. Beebe DW, Gozal D. Obstructive sleep apnea and the prefrontal cortex: towards a comprehensive model linking nocturnal upper airway obstruction to daytime cognitive and behavioral deficits. J Sleep Res. 2002;11(1):1-16.

110. Carmeliet P, Dor Y, Herbert JM, et al. Role of HIF1 $\alpha$ in hypoxia mediates apoptosis, cell proliferation and tumor angiogenesis. Nature. 1998;394(6692):485-490.

111. Almendros I, Montserrat JM, Ramírez J, et al. Intermittent hypoxia enhances cancer progression in a mouse model of sleep apnoea. Eur Respir J. 2012;39(1):215-217.

112. Nieto FJ, Peppard PE, Young T, Finn L, Hla KM, Farré R. Sleep disordered breathing and cancer mortality: results from the Wisconsin Sleep Cohort Study. Am J Respir Crit Care Med. 2012;186(2):190-194.
113. Liu Y, Song X, Wang X, Wei L, Liu X, Yuan S, Lv L. Effect of chronic intermittent hypoxia on biological behavior and hypoxiaassociate gene expression in lung cancer cells. J Cell Biochem. 2010;111(3):554-563.

114. Almendros I, Wang Y, Becker L, et al. Intermittent hypoxia-induced changes in tumor-associated macrophages and tumor malignancy in a mouse model. Am J Respir Crit Care Med. 2014;189(5):593-601.

115. Gozal D, Farré R, Nieto FJ. Putative links between sleep apnea and cancer: from hypotheses to evolving evidence. Chest. 2015;148(5): 1140-1147.

116. Campos-Rodriguez F, Martinez-Garcia MA, Martorelli-Calatayaud A, et al. Association between markers of aggressiveness of malignant cutaneous melanoma and sleep-disordered breathing. Eur Respir J. 2013;42:639s.

\section{Hypoxia}

\section{Publish your work in this journal}

Hypoxia is an international, peer-reviewed, open access journal that aims to improve understanding of the biological response to hypoxia. The journal will publish original research articles, reviews, methodological advances, clinical studies, and expert opinions that identify developments in the regulation of the physiological and pathological responses to

Submit your manuscript here: http://www.dovepress.com/hypoxia-journal

\section{Dovepress}

hypoxia and in the therapeutic targeting of hypoxia-responsive pathways. The manuscript management system is completely online and includes a very quick and fair peer-review system, which is all easy to use. Visit http://www.dovepress.com/testimonials.php to read real quotes from published authors. 